\title{
A DANÇA NA PROPOSTA CURRICULAR DE SANTA CATARINA (2014)
}

\author{
Cristiane Moreira Eugênio ${ }^{1}$ \\ Bruna Carolini De Bona ${ }^{2}$ \\ Francine Costa De Bom ${ }^{3}$
}

\section{RESUMO}

Orientadas pelo problema de compreender como se configura o conteúdo dança inserido na Proposta Curricular de Santa Catarina no ano de 2014, nosso objetivo foi analisar o conteúdo dança no documento a partir das disciplinas de Artes e Educação Física, evidenciando os possíveis afastamentos e aproximações em relação aos componentes, ao tratar do conteúdo dança. A pesquisa se caracteriza como documental orientada pela análise do documento orientador do currículo em Santa Catarina. Concluímos que a dança se apresenta de modo distinto em ambas as disciplinas, evidenciando contrapontos entre a dança como forma de arte e a dança como prática corporal.

Palavra-chave: Dança; Educação Física; Artes; Currículo.

\section{THE DANCE IN "PROPOSTA CURRICULAR DE SANTA CATARINA"}

(2014)

\begin{abstract}
Guided by the problem to understanding how to configure the dance content inserted in the "Proposta Curricular de Santa Catarina" in the year 2014 our objective was analyzed the dance content in the document from the art and physical education subjects evidencing the possible distances and the approximations in relation to the components dealing with the dance content. The research is characterized as documentary oriented by the analysis of the guiding of the Curriculum in Santa Catarina. It was conclude that the dance presents itself differently in both subjects evidencing counterpoints between the dance as an art form and the dance as body practice.
\end{abstract}

Keywords: Dance, Physical Education, Arts, Curriculum.

\footnotetext{
1 Acadêmica do curso de Educação Física da UNESC, Bolsista de Iniciação Cientifica PIC 170. Email.krizinhaedf@hotmail.com

${ }^{2}$ Possui graduação em Educação Física pela Universidade do Extremo Sul Catarinense (2013) e Mestrado em Educação pela mesma Universidade. Atua como professora no curso de Educação Física na Universidade do Extremo Sul Catarinense. Email: bcb@unesc.net.

${ }^{3}$ Mestra em Ciências da Linguagem pela UNISUL (Universidade do Sul Catarinense). Professora de graduação no curso de Licenciatura e Bacharelado em Educação Física na Universidade do Extremo Sul Catarinense (UNESC) Email: costafrancine@hotmail.com
}

Criar Educação, Criciúma, v. 7, no1, jan/jul 2018.- PPGE - UNESC 


\section{INTRODUÇÃO}

Pela possibilidade de dançar na escola, muitos alunos acabam despertando o desejo pela dança enquanto formação acadêmica. Na região sul de Santa Catarina, o desejo acompanha a falta de formação específica na área da dança, o que leva muitos desses alunos a formação no campo da Educação Física escolar. Esse mesmo desejo orientou nossa formação e nos leva hoje a pesquisar sobre a dança enquanto conteúdo da Educação Física na escola.

Durante a trajetória acadêmica, principalmente nos estágios obrigatórios ${ }^{4}$, percebemos o quanto esse conteúdo ainda não é legitimado na escola. O primeiro estágio na Educação Infantil foi elaborado com o tema de dança e ginástica, uma experiência gratificante e ao mesmo tempo preocupante, pois os conteúdos elaborados não faziam parte do cotidiano das crianças. Isso nos deixa incomodada ao perceber o quanto a dança é ainda distante dos alunos. Os mesmos relatavam que gostavam, porém não lhe era oportunizado.

Analisando os estudos Marques (2007a), podemos perceber que a autora enfatiza um ensino de dança crítico e transformador, que discuta as relações multifacetadas entre corpo, escola, indivíduo, arte e sociedade contemporânea. A autora aponta fatores que influenciam para que a dança não se efetive de maneira continua e sistematizada no ensino escolar. Dentre esses fatores inclui-se o comportamento ainda tradicional das escolas ao tratar do corpo e da arte, o preconceito existente no campo da dança, a falta de conhecimento sobre esse conteúdo e a formação de professores associada a esse conhecimento. Como aponta Marques (2007a), a maioria das vezes os professores não sabem exatamente o que ou, até mesmo, porque ensinar dança na escola.

Da mesma forma, Salvador (2013) aponta que a evolução do pensamento sobre o corpo evolui em conjunto com a humanidade, levando em conta que o corpo

\footnotetext{
${ }^{4}$ Os estágios do curso de Educação Física - Licenciatura da Universidade do Extremo Sul Catarinense (UNESC) tem por objetivo geral possibilitar as condições necessárias para que 0 acadêmico (a) se reconheça como professor (a) de Educação Física, mediador (a) entre o conhecimento da cultura corporal de movimento e os alunos, mediante inserção teórico-prática na totalidade do trabalho escolar, considerando a formação científica, cultural, humana e ética desenvolvida ao longo do curso de licenciatura.
} 
está, e sempre esteve, atrelado à moral e à personalidade do homem, questões controladas e ditadas pela religião e pela política, impondo o "certo e o errado".

Por isso, buscamos nesse artigo compreender a dança como conteúdo na Proposta Curricular de Santa Catarina (2014). Inicialmente, analisamos a importância da análise desse documento, destacando sua atualidade e importância enquanto proposta curricular do Estado de Santa Catarina.

A atualização da Proposta Curricular do Estado de Santa Catarina ocorre em face dos desafios contemporâneos que permeiam o campo educacional, ao mesmo tempo em que se reconhecem a pertinência e a atualidade das suas bases teórico-metodológicas. (SANTA CATARINA, 2014, p. 19).

No mesmo sentido, identificamos que o mesmo aborda a dança tanto na disciplina de Educação Física, quanto na disciplina de Artes. Por isso, nos colocamos a analisar também essa suposta dualidade do conteúdo em ambas as disciplinas, buscando superar uma errônea diferenciação.

Delimitamos o seguinte problema: de que forma a dança é abordada na Proposta Curricular de Santa Catarina (2014)? Nosso objetivo geral foi o de analisar o conteúdo dança na Proposta Curricular de Santa Catarina (2014), elencando como objetivos específicos: 1) compreender o conteúdo dança tratado pela disciplina de Artes; 2) compreender o conteúdo dança tratado pela Educação Física; 3) Analisar os pontos de convergência e divergência entre ambos.

A pesquisa caracteriza-se como pesquisa documental, analisando o documento balizador da organização curricular da Educação Básica catarinense. Segundo Sá-Silva, Almeida e Guindani (2009, p. 5), a pesquisa documental caracteriza-se como um "procedimento que se utiliza de métodos e técnicas para apreensão, compreensão e análise de documentos dos mais variados tipos".

Para análise do documento, evidenciamos algumas unidades que orientam esse estudo. Buscaremos compreender a dança, dialogando com a disciplina de Artes e Educação Física, a partir dos temas: o conceito dança evidenciado por ambas as disciplinas; a importância da dança na escola e as orientações para o trato deste conteúdo em ambas as disciplinas.

Para orientar nossa análise, nos baseamos em Marques (2007 a, 2007 b) e Barreto (2008). Buscando valorizar a importância da dança na escola, enfatizando 
a relevância em discutir esse conteúdo a partir do documento orientador do currículo em Santa Catarina.

\section{A ÁREA DE LINGUAGENS E SEUS CONCEITOS ARTICULADORES}

Na Proposta Curricular de Santa Catarina (2014), a área de linguagens, assim como as demais áreas, busca evidenciar conceitos que articulam os diferentes componentes, buscando superar a fragmentação e o etapismo que por vezes orienta a organização do currículo. Segundo Santa Catarina (2014) a fragmentação do conhecimento é incapaz de dar conta da problemática social e do cotidiano da escola. No mesmo sentido afirma:

[...] preservamos a identidade das disciplinas escolares, mas escolhemos fazer um percurso de pensá-las agrupadas em 'áreas' do conhecimento como um exercício inicial para caminharmos na compreensão de uma formação integral num percurso formativo menos fragmentado. (SANTA CATARINA, 2014, p. 93).

A área tematiza conceitos articuladores, que se interligam com os componentes Artes, Educação Física, Língua Portuguesa, Língua Materna para populações indígenas e usuários de Libras e Línguas Estrangeiras. Esse conjunto de conceitos científicos integradores tem como centro o conceito de semiose, concebido como o conceito integrador dos signos verbais e não verbais que constituem as linguagens, diante de suas modalidades: áudio-oral, escrita, visogestual, tátil, imagética e de movimento.

Segundo o Coletivo de Autores (1992), a dimensão corpórea se materializa na linguagem, no trabalho e no poder, as três atividades produtivas da história da humanidade. "É linguagem um piscar de olhos enquanto expressão de namoro e concordância [...], uma dança enquanto expressão de luta, de crenças. Com as mãos os surdos se comunicam pela linguagem gestual". (COLETIVO DE AUTORES, 1992, p. 39). Considera-se que os sujeitos utilizam diferentes linguagens nas situações reais do dia a dia, caracterizadas por valores, vivências, traços culturais, políticos sociais, econômicos, a partir de sua maneira de ver o mundo.

Buscamos na sequência, portanto, evidenciar a dança na perspectiva da área de linguagens, buscando preservar a identidade do conteúdo relacionado às Criar Educação, Criciúma, v. 7, no1, jan/jul 2018.- PPGE - UNESC 

cultural.

\title{
2.1 A dança na perspectiva da Educação Física na Proposta Curricular de Santa Catarina (2014)
}

Apresentamos inicialmente o contexto da dança apresentado por Santa Catarina (2014) associado aos conceitos articuladores da disciplina de Educação Física. Para a proposta, a organização da cultura corporal do movimento se dá por meio da brincadeira, do esporte, da dança, do jogo, da ginástica e das lutas.

\begin{abstract}
O professor deve estimular e aprofundar os estudantes, a compreensão crítica e reflexiva acerca das práticas constitutivas da cultura corporal do movimento, que instauram os diferentes modos de dizer produzidos por diferentes grupos sociais, cada um com suas próprias representações de mundo e valorações. (SANTA CATARINA, 2014, p. 109).
\end{abstract}

Segundo o documento, na história da Educação Física, solidificou-se como conceito balizador a cultura corporal do movimento. Utilizando a linguagem corporal como referência constitutiva, essa é compreendida como um conjunto de práticas corporais que possui na linguagem corporal sua referência. (SANTA CATARINA, 2014). Referente a essas práticas, os conteúdos da Educação Física evidenciados pelo documento são: jogos, lutas, danças, ginástica e outras práticas corporais de caráter ludo-motriz. Sobre a dança, a proposta destaca:

\begin{abstract}
À medida que novas correntes surgem no âmbito dessa prática corporal, o conceito se alarga e deixa de ser restrito à dimensão técnica. Dessa forma, passa-se a enfatizar a dança como uma prática corporal na qual o elemento central é a veiculação de ideias e sentimentos na linguagem corporal. A produção de sentidos na dança acontece à medida que se supera uma concepção dualista de ser humano, assumindo que o corpo expressa aquilo que somos. (SANTA CATARINA, 2014, p. 134).
\end{abstract}

A proposta enfatiza que a dança deve ser compreendida de tal forma a criar expressões singulares, o que, segundo o documento, não se reduz ao campo da Educação Física, mas também a disciplina de Artes. Os consultores do documento ressaltam a necessidade de instaurar a criatividade como centro do processo de desenvolvimento da dança, pois as formas padronizadas de 
movimentos ritmados não possibilitam a compreensão crítica dos diversos gêneros de danças tematizados.

De modo geral, segundo Santa Catarina (2014), a Educação Física é um espaço democrático para apropriação do conhecimento sobre a cultura corporal do movimento, enfatizando o respeito aos valores tais como solidariedade, inclusão e respeito às diferenças. A proposta afirma que as práticas da cultura corporal do movimento devem ser abordadas tanto na dimensão do saber fazer, quanto do saber teórico sobre elas, almejando uma mudança de compreensão que transcenda o senso comum para uma compreensão baseada no senso crítico.

Em relação à organização da cultura corporal do movimento, a proposta ressalta a importância da dança no percurso formativo, demonstrando que a mesma deve ser tematizada relacionando saúde, lazer, recreação, discutindo sua relação com as competições, diversidade, valorações e implicações ideológicas.

$\mathrm{Na}$ Educação Física, compreende-se que as práticas sociais devem estar vinculadas aos sentidos que ligam os participantes a uma ordem social determinada. A proposta destaca como exemplo as discussões dos gêneros que permeiam o conteúdo dança, considerando os sentidos que nele se apresentam e que se vinculam a determinados grupos sociais e sua respectiva visão de mundo.

\begin{abstract}
No caso das danças de rua, com destaque para o hip-hop e os estilos que Ihe são constitutivos, manifesta-se uma maneira peculiar de ver o mundo; nelas se faz presente um modo específico de linguagem corporal que retrata modos de relação com o corpo e com o outro, um diálogo centrado no movimento corporal que pressupõe a criatividade, a ousadia, a disputa, a transgressão, dentre os elementos mais destacados. (SANTA CATARINA, 2014, p. 116).
\end{abstract}

Em uma discussão sobre função e forma, a dança tradicionalmente é vista como movimento ritmado, dentro de um ponto de vista técnico, não considerando os sentidos e significados que a orientam. Segundo o documento, quando novas correntes surgem a pensar essa prática, o conceito se amplia e não se restringe apenas a dimensão técnica. Busca-se abordar a dança como uma prática corporal utilizando como elemento central a condução de idéias e sentimentos a partir da linguagem corporal.

Criar Educação, Criciúma, v. 7, no1, jan/jul 2018.- PPGE - UNESC 
A produção de sentidos na dança se dá por meio de uma superação da concepção dualista do ser humano, assumindo que o corpo expressa aquilo que somos. A Proposta destaca que:

\begin{abstract}
$\mathrm{Na}$ produção de uma coreografia de dança ou em uma atividade de improvisação, o que está em jogo é um modo particular de ver e dizer o mundo, para cuja produção a música e os movimentos ritmados podem ser um recurso importante (porém não imprescindível). Por outro lado, a dança deve ser compreendida como uma prática, na qual a produção de modos singulares de expressão deve ser promovida, o que já foi discutido neste documento no âmbito da Arte. (SANTA CATARINA, 2014, p. 134).
\end{abstract}

Para Santa Catarina (2014), a metodologia de aprendizagem da dança precisa ser modificada, possibilitando instaurar a criatividade no centro do processo, permitindo uma compreensão crítica dos diversos gêneros da dança tematizados, minimizando a tradição padronizada do ensino da dança.

\title{
2.2 A dança na perspectiva da Arte na Proposta Curricular de Santa Catarina (2014).
}

Em relação aos conteúdos da disciplina de Artes, a proposta afirma que a escolha destes deve levar em consideração os diversos grupos artísticos constituintes no contexto brasileiro e internacional, compreendendo que a dança possibilita estudos de manifestações para se pensar a Arte como um artefato histórico-cultural. (Santa Catarina, 2014).

A Proposta afirma que:

\begin{abstract}
Possibilitar aos estudantes o contato com o objeto artístico, ou meios de aproximação com o objeto, contribui para que possam ampliar seu repertório cultural, aprendendo a analisar, refletir, posicionar-se criticamente, emitindo opiniões sobre estilos, gostos, gêneros, materialidades e os diversos modos de fazer Arte. (SANTA CATARINA, 2014, p. 113).
\end{abstract}

Partindo das relações interpessoais, a Proposta de Santa Catarina (2014) aponta que deve ser proporcionado aos sujeitos da Educação Básica, subsídios que permitam diferenciar o valor cultural de uma obra de arte do valor estético, compreendendo que a ligação entre estética e cultura, juntamente com suas contradições e sobreposições, fornecem dinamismo ao objeto artístico.

Criar Educação, Criciúma, v. 7, ำ1, jan/jul 2018.- PPGE - UNESC 
Sobre a dança, segundo Santa Catarina (2014, p. 112):

\begin{abstract}
Nessas relações, o sujeito apropria-se de novas representações em Arte: novos modos de significar ver, sentir, entender e criar formas visuais; compreender os movimentos expressivos através da dança; ver, sentir ou produzir representações teatrais que tematizem situações de vida carregadas de sensibilidade, drama, comicidade, suspense; apreciar uma produção musical ou mesmo criar uma letra e adaptá-la a um estilo musical, combinar ou apreciar a harmonização de instrumentos que caracterizam diferentes povos e culturas, isso sempre na sociointeração. (SANTA CATARINA, 2014, p. 112).
\end{abstract}

É preciso que o professor conheça as características do seu grupo e elabore diferentes maneiras de interação com o objeto artístico, compreendendo os tempos de aprendizagem na Educação Básica, assim como as pessoas com deficiência, transtornos globais do desenvolvimento e altas habilidades ou superdotação. (SANTA CATARINA, 2014). Compreendendo que cada linguagem tem elementos que a caracterizam e a compõem de forma diferenciada, seja ela no âmbito da arte visual, na música, no teatro ou na dança, cada uma articulando com ferramentas e suportes.

\title{
3. ANÁLISE DA DANÇA NA PROPOSTA CURRICULAR DE SANTA CATARINA
} (2014)

Iniciaremos nossa análise aprofundando o conceito de dança destacado pela disciplina de Artes e pela Educação Física no documento estudado. Segundo Santa Catarina (2014), na área da Educação Física, a dança é considerada uma prática corporal na qual o elemento central é a veiculação de idéias e sentimentos na linguagem corporal.

Já o componente Artes (SANTA CATARINA, 2014) entende a dança como o movimento que ampara a criação artística, expressando o que o dançarino deseja manifestar, sendo o corpo o meio e suporte pelo qual a arte intercede as relações entre artistas e interlocutores.

Analisando os conceitos trazidos por cada componente, verificamos que para a Educação Física, a dança vem conceituada como prática corporal, o que a limita como atividade, destacando-a como uma prática do corpo. Já na disciplina de Arte, os autores consideram que a dança é um movimento que dá base a criação artística.

Criar Educação, Criciúma, v. 7, ㄲo1, jan/jul 2018.- PPGE - UNESC 
Importante mencionar que no campo da Educação Física a ideia da criação artística não se apresenta, aparecendo apenas no campo da Arte.

Verificamos que para área de Educação Física o conceito de prática corporal ainda está muito associado à dança, reduzindo-a suas possibilidades perante o desenvolvimento dos alunos. Ressaltamos que, em nenhum momento a Educação Física destaca a importância do campo artístico relacionado à dança na escola. Nesse sentido a dança como forma de arte perde espaço na escola, sendo tratada apenas por um aspecto prático e motor, e não na sua totalidade.

Isso nos chama atenção, pois percebemos que no campo da Educação Física ganha ênfase a dança como possibilidade prática de conteúdo, sendo que em Artes evidenciamos a centralidade da dança como linguagem da Arte. Essa diferenciação nos sugere que é possível diferentes "tipos" de dança na escola: aquela associada a Educação Física e outra associada a Artes. Afirmamos, no entanto, que a atividade de dança, desenvolvida historicamente pelos homens é a mesma em ambos os componentes, sendo errônea essa suposta divisão do conteúdo.

Evidenciamos, também, elementos comuns nas conceituações apresentadas. A Educação Física vai dizer que a dança é um veículo para transmissão de ideias e sentimentos para as pessoas. Da mesma forma, em Artes, a criação artística tem como objetivo expressar o que o dançarino deseja manifestar, ou seja, estabelecer relação com o público.

Segundo Marques (2007a), a dança é uma forma de Arte imprescindível na formação de "corpos" criativos e críticos. A autora critica as abordagens de dança associadas ao espontaneísmo e nos chamados processos de criação "natural" dos alunos, pois acabam por negar conteúdos e saberes da dança. Para Barreto (2008), dançar é uma forma de conhecer que envolve o ser em toda sua amplitude, sensibilidade e racionalidade. A autora revela a dança como diálogo de corpos, definida como processo de comunicação, educação e transformação.

Após analisado o conceito, passamos a indicar a importância da Dança na escola em ambos os componentes. Sobre isso, Santa Catarina (2014) afirma que

A Educação Física escolar tem importante papel na formação para o lazer, a recreação e a brincadeira. O lazer, como fenômeno moderno, leva a problematizar as práticas desenvolvidas no tempo do não-trabalho remunerado. Com o desenvolvimento da modernidade a oferta de práticas

Criar Educação, Criciúma, v. 7, ำ1, jan/jul 2018.- PPGE - UNESC 

CATARINA, 2014, p. 105).

O documento ressalta que a Educação Física não pode ser relegada a uma reflexão meramente teórica sobra as práticas corporais, sendo que sua identidade pedagógica se funda no pensar, no fazer e no sentir corporal. O documento enfatiza a importância da formação do estudante para que se reconheça como produto e produtor de cultura na relação com o outro, contribuindo para a formação integral do sujeito. A Educação Física, na proposta, visa o desenvolvimento da autonomia, cooperação, da participação social, permitindo que o aluno vivencie diferentes práticas corporais das mais diversas manifestações culturais, através de uma compreensão critica associada às implicações éticas e estéticas de cada uma.

No âmbito da Arte, o documento enfatiza a importância de possibilitar aos estudantes o contato com o objeto artístico, ampliando seu repertório cultural, aprendendo a analisar, refletir e se posicionar criticamente, sendo capaz de emitir opiniões sobre gostos, gêneros, estilos e os diversos modos de fazer arte.

\begin{abstract}
Nessas relações, o sujeito apropria-se de novas representações em Arte: novos modos de significar ver, sentir, entender e criar formas visuais; compreender os movimentos expressivos através da dança; ver, sentir ou produzir representações teatrais que tematizem situações de vida carregadas de sensibilidade, drama, comicidade, suspense; apreciar uma produção musical ou mesmo criar uma letra e adaptá-la a um estilo musical, combinar ou apreciar a harmonização de instrumentos que caracterizam diferentes povos e culturas, isso sempre na sociointeração. (SANTA CATARINA, 2014, p. 112).
\end{abstract}

Evidenciamos, portanto, que na área da Educação Física, embora o documento apresente a importância dos conteúdos da Educação Física para a formação integral dos sujeitos, ressaltamos novamente a concepção de apropriação dos conteúdos enquanto práticas corporais, fazendo com que o aluno vivencie esses conteúdos. O documento, também, afirma a importância de destacar no percurso formativo a tematização dos conteúdos relacionados ao lazer, saúde e recreação. Novamente, se desconsidera a possibilidade de apropriação de conhecimento nas aulas de Educação Física e de sua importância real na formação integral dos alunos.

$\mathrm{Na}$ disciplina de Artes, observamos a importância da Dança como possibilidade de ampliar o repertório cultural, possibilitando ao mesmo analisar,

Criar Educação, Criciúma, v. 7, ำ1, jan/jul 2018.- PPGE - UNESC 
refletir e se posicionar de maneira crítica sobre os modos de fazer Arte. No mesmo sentido, Marques (2007b) reconhece que o ensino da dança engloba conteúdos mais amplos e complexos, não se limitando apenas ao simples dançar na escola.

De tal forma que a autora critica as abordagens de dança que se reduzem apenas a finalidade de relaxamento, expressão e liberação de emoção dos alunos, ou até mesmo para melhorar a coordenação motora dos mesmos. Para a autora, a afirmação de que dançar se aprende dançando é uma postura ingênua em relação aos inúmeros significados incorporados à dança.

Marques (2007b) aborda a importância de um olhar mais crítico sobre a dança na escola, nos questionando sobre o real papel da dança nesse espaço.Enfatiza uma postura crítica em relação ao ensino da dança que envolve conteúdos amplos e complexos. Conteúdos esses que a autora, apoiada nos estudos de Rudolf Laban ${ }^{5}$, configura em textos e contextos da dança.

O contexto aborda os saberes sobre a dança ou conhecimento indireto da arte sendo eles, elementos históricos, culturais, sociais, estéticos, sociológicos, musicais, etc. Ao tratar dos textos nos reportamos ao conhecimento direto da dança, sendo a improvisação, composição coreográfica, o repertório, permitindo a presença da dança como arte nos processos educativos.

Segundo Barreto (2008), a dança, como uma expressão artística, possui por objetivo estimular a sensibilidade dos educandos, promovendo a descoberta do próprio corpo.

$\mathrm{O}$ ato de dançar como o que revela a essência dos medos, mistérios e riscos, transformando e representando o que não pode ser senão expressividade humana dinâmica e efêmera, como um vento que sopra forte, um conceito de dança que seja como a poesia, que não pode ser explicada, mas apenas sentida e interpretada. (BARRETO, 2008, p. 125).

Podemos analisar que a importância da dança na escola é tratada ao evidenciar a relevância da presença das disciplinas na mesma, evidenciando diferenças nesses pontos. De qualquer forma, se busca afirmar a contribuição de ambas para o percurso formativo, demostrando a relevância da ampliação das

\footnotetext{
${ }^{5}$ Rudolf Laban foi dançarino, coreógrafo, teatrólogo, musicólogo, considerado o maior teórico da dança do século XX. Dedicou sua vida ao estudo à sistematização da linguagem do movimento em seus diversos aspectos.
}

Criar Educação, Criciúma, v. 7, ำ1, jan/jul 2018.- PPGE - UNESC 
manifestações culturais no campo da Educação Física e do repertório cultural no campo da Arte. A dança se encontra assim, afirmada em ambos os contextos.

No mesmo sentido, apontamos os objetivos que orientam ambas as disciplinas em Santa Catarina (2014). No campo da Educação Física, a disciplina tem por objetivo promover a apropriação crítica das práticas corporais, pela mediação pedagógica das práticas da cultura corporal do movimento. Considera valores tais como: inclusão, solidariedade, igualdade, alteridade e o reconhecimento as diferenças.

A disciplina de Artes tem por objetivo promover a possibilidade de o estudante posicionar-se criticamente diante da produção artística de seu tempo, considerando o contato crítico com a Arte. Especificamente se tratando da dança, é preciso que o professor esteja atento as características do seu grupo e pesquise diferentes maneiras de interação com o objeto artístico, possibilitando ao aluno que vivencie diversos tipos de produção artística.

Para Marques (2007) a contribuição da dança é a de educar corpos que sejam capazes de criar pensando e ressignificar o mundo em forma de arte. A dança, como forma de arte, está engajada com sentimento cognitivo e não apenas com sentimento afetivo. Barreto (2008) busca revelar a dança como diálogo de corpos, definindo-a como um processo de comunicação, educação e transformação. Ressalta que a escola deve proporcionar ao aluno a capacidade de sentir, pensar e agir no mundo compreendendo-se como cidadão.

Passamos a apresentar de que forma é a presentado o trato da dança em cada disciplina, evidenciando a organização das aulas a partir desse conteúdo. Para a Arte, cada obra de arte (música, teatro, dança, entre outros) marca um processo que se articulam suportes, ferramentas e matéria. Sendo assim, a Arte como conhecimento, agrega a experiência de se aprender por meio da produção dos outros, possibilitando reconhecer como se dá a produção artística. Na dança, é o corpo do artista que possibilita o gesto, o movimento que sustenta a criação artística. Sendo assim,

Formas, cores, linhas, texturas, luz, sombra e os espaços, entre outros recursos materiais, são elementos visuais que precisam ser compreendidos e manipulados para que os sujeitos possam por meio deles elaborar a linguagem. A linguagem escolhida marcará e caracterizará o suporte, a

Criar Educação, Criciúma, v. 7, nº1, jan/jul 2018.- PPGE - UNESC 
escolha das ferramentas e a matéria em si. (SANTA CATARINA, 2014, p. 130).

Deve-se, então, garantir a apropriação crítica dos conceitos cênicos, dramáticos e espaciais, que mobilizem a integração entre percepção, imaginação, intuição, memória, emoção e outros constituintes das linguagens artísticas.

Para a Educação Física, o primeiro ponto a ser mencionado refere-se à importância de partir da compreensão geral das atividades, permitindo ao aluno compreender o princípio que funda a forma geral para depois contextualiza-lo de maneira concreta a partir de seu uso em uma determinada prática social. Sobre a dança, o documento menciona que a tradição do ensino da dança calcada em formas padronizadas de movimentos ritmados precisa ser ressignificada para instaurar a criatividade como centro do processo.

\footnotetext{
Isso não significa negligenciar as formas culturalmente objetivadas dos diferentes gêneros de danças produzidas historicamente pela humanidade, mas pressupõe que a prática pedagógica da Educação Física escolar deve permitir a compreensão crítica dos diversos gêneros de dança tematizados, situando-se no seu devir sócio-histórico, permitindo abertura para novas leituras possíveis. (SANTA CATARINA, 2014, p. 134).
}

Marques (2007a) evidencia a importância de se repensar as metodologias que se baseiam na criação natural do aluno, afirmando que a dança vai além do ato de dançar. Um ponto crítico considerado por Marques (2007a) é a formação dos professores em relação à dança. Muitas vezes permanece a concepção de que a dança serve para relaxar, conter a agressividade, melhorar a coordenação motora. Segundo a autora, a escola tem a possibilidade de fornecer subsídios para sistematização e apropriação crítica, de forma consciente e transformadora dos conteúdos específico de dança, devendo ser utilizado para transformar a própria dança e também a sociedade. Para Salvador (2013, p.39),

[...] os estudos do movimento na dança passam, não só por suas relações com o social, com cultural ou com o físico, mas instigam, também, a pensar em signos, em narrativa em possibilidades de comunicação e expressão através desse corpo que é soma.

Segundo Barreto (2008) não basta saber o que ensinar, é imprescindível que se compreenda para que e o porquê destes atos. Para a autora, uma metodologia de dança deve ir além do incorporar as estruturas teóricas práticas utilizadas, tal

Criar Educação, Criciúma, v. 7, ำ1, jan/jul 2018.- PPGE - UNESC 
como instrumentos, métodos e técnicas, tendo ela a possibilidade de estimular reflexões e ações críticas e mais sensíveis no aluno diante do mundo em que vivem.

\section{CONSIDERAÇÕES FINAIS}

A Proposta Curricular de Santa Catarina (2014) se apresenta como um documento de grande importância para a educação catarinense, pois orienta o currículo do estado e afirma uma proposta crítica dos processos de ensino e aprendizagem. Enfatizamos que a mesma precisa ser estudada e analisada por todos no âmbito educacional, sendo referência para as ações desenvolvidas na escola.

Santa Catarina (2014) demonstra avanços ao colocar as áreas de conhecimento em diálogo e articulação, ressaltando a importância de um percurso formativo menos fragmentado como princípio para uma formação integral. No entanto, percebemos que essa articulação pouco se efetiva na escola e também no documento, verificando que o conceito de dança se apresenta de modos distintos no documento.

Nossa análise destaca elementos que consideramos importantes a serem avaliados. Iniciamos com o conceito de dança e concluímos que a Educação Física ressalta os conteúdos da Educação Física como práticas corporais. Em Artes, respeitando o campo de formação, analisamos questões que nos fazem refletir sobre a dança como uma linguagem da Arte, o que pode qualificar o trabalho dos mesmos no campo escolar, já que, em nossa região, avaliamos um distanciamento dos professores em relação a esse conteúdo na escola. A pesquisa de Pereira (2016) aponta que o espaço da dança nas aulas de Arte num município da região sul catarinense, ainda se volta às festividades da escola, afim de "enfeitar" tais eventos. Segundo a autora, a partir do discurso dos professores de Arte, não se configura o exercício da linguagem da dança nessas aulas.

Dos autores que nos deram base nesse artigo, foi possível perceber que os mesmos almejam uma metodologia de ensino pelo qual o aluno se aproprie da dança de tal forma que possa se desenvolver criticamente e artisticamente. De acordo com os autores, a falta de conhecimento de alguns professores sobre o

Criar Educação, Criciúma, v. 7, nº1, jan/jul 2018.- PPGE - UNESC 
ensino da Dança é uma razão pela qual, muitos ainda não trabalham com a dança na escola.

Fica evidente o quanto a dança ainda tem que avançar tanto na Educação Física quanto na Arte. A formação de professores com certeza é o melhor caminho. Além de se apropriar de um conhecimento, o professor adquire confiança e segurança em lecionar o conteúdo. Destacamos a importância desse conteúdo nas escolas e a necessidade de aprofundar a dança tanto na disciplina de Artes, quanto na disciplina de Educação Física, assim como do documento que orienta o currículo em Santa Catarina.

\section{REFERÊNCIAS}

BARRETO, Débora. Dança...: ensino, sentidos e possibilidades na escola. $3^{a}$ ed. Campinas, São Paulo: Autores Associados, 2008.

COLETIVO DE AUTORES. Metodologia do Ensino de Educação Física. São Paulo: Cortez, 1992.

MARQUES, Isabel A. Dançando na escola. 4ª ed. São Paulo: Cortez, 2007a.

. Ensino De Dança Hoje. 4ª ed. São Paulo: Cortez, 2007b.

Salvador, Gabriela Di Donato. Histórias e propostas do corpo em movimento: um olhar para a dança na educação. Guarapuava: Unicentro, 2013

SANTA CATARINA. Governo do Estado. Secretaria do Estado da Educação.

Proposta Curricular de Santa Catarina: formação integral na educação básica / Estado de Santa Catarina, Secretaria de Estado da Educação, 2014.

SÁ-SILVA J.R, ALMEIDA C.D, GUINDANI J.F. Pesquisa documental: pistas teóricas e metodológicas. Revista Brasileira de História \& Ciências Sociais, julho de 2009.

OLIVEIRA, Jhenifer Pereira. A linguagem da dança nas aulas de Arte nas escolas municipais em Içara. 2016. Monografia - Curso de licenciatura em Arte da Universidade do Extremo Sul Catarinense, Criciúma, 2016. 